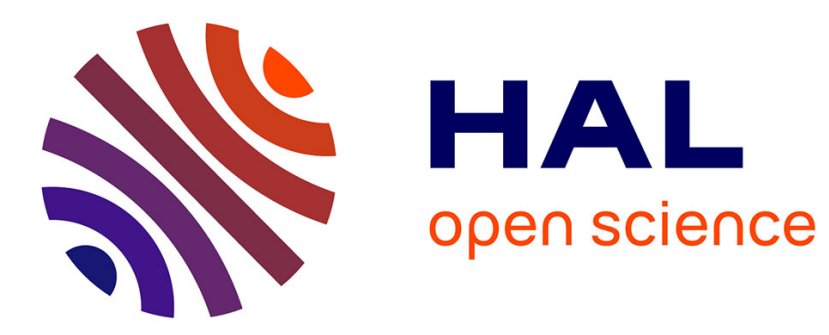

\title{
DISSOCIATION AND PLASTICITY OF COVALENT CRYSTALS
}

\author{
H. Alexander
}

\section{To cite this version:}

H. Alexander. DISSOCIATION AND PLASTICITY OF COVALENT CRYSTALS. Journal de Physique Colloques, 1974, 35 (C7), pp.C7-173-C7-180. 10.1051/jphyscol:1974719 . jpa-00215875

\section{HAL Id: jpa-00215875 https://hal.science/jpa-00215875}

Submitted on 1 Jan 1974

HAL is a multi-disciplinary open access archive for the deposit and dissemination of scientific research documents, whether they are published or not. The documents may come from teaching and research institutions in France or abroad, or from public or private research centers.
L'archive ouverte pluridisciplinaire HAL, est destinée au dépôt et à la diffusion de documents scientifiques de niveau recherche, publiés ou non, émanant des établissements d'enseignement et de recherche français ou étrangers, des laboratoires publics ou privés. 


\title{
DISSOCIATION AND PLASTICITY OF COVALENT CRYSTALS
}

\section{H. ALEXANDER}

\author{
Abt. für Metallphysik im II. Phys. Inst. der Univ. Köln W-Germany.
}

\begin{abstract}
Résumé. - Après avoir discuté la structure de cour des différents types de dislocations dans la structure diamant, on résume les observations expérimentales concernant l'existence et la mobilité de dislocations dissociées dans le silicium et le germanium. On suppose que des sources, fonctionnant selon un mécanisme de pôle à un seul bras, suffisent à produire des fautes d'empilement superposées et des mâcles de déformation. On discute l'apparition de bandes de glissement se terminant en éventail, et les résultats d'essais de durcissement latent.
\end{abstract}

\begin{abstract}
After a discussion of the core structure of various types of dislocations in the diamond structure the experimental evidence is summarized for the existence and mobility of dissociated dislocations in silicon and germanium. Single armed pole sources are supposed to produce stacks of stacking faults and deformation twins. The fanning of glide bands and the results of latent hardening experiments are discussed.
\end{abstract}

1. Introduction. - The plastic properties of a crystal are determined by the glide systems of its lattice and by the structure and mobility of the individual dislocation. Going from fcc metals to crystals with diamond structure like silicon and germanium we keep the Bravais lattice but we change to directed and localized bonds. As a consequence, investigating the plastic deformation of germanium we shall find in some respects the properties of an ideal fcc metal, in others quite a different behaviour. Since out of the covalently bonded substances those with diamond structure are most extensively [1] investigated only these will be described in the following.

2. Structural aspects. - The diamond structure is developed from the fcc lattice by inserting a second fcc (sub)lattice displaced by $\frac{\mathrm{a}}{4}[111]$ from the original lattice points. The closed packed (111) planes of the second sublattice do not lie half-way between those of the first sublattice. So we get some kind of a layer structure : the (111) planes form double layers the distance between two layers being three times as large as the distance of the two planes constituting one layer (Fig. 1). As usual the stacking positions of the (111) planes in the fec lattice are labeled $A B C A B C .$. Both sublattices take the same stacking positions, the change from $\mathrm{A}$ to $\mathrm{B}$, etc. taking place between the two planes of one layer. Figure 1 shows the stacking sequence designating one sublattice with capitals, the other with small letters; in addition can be seen the arrangement of covalent bonds per atom within (three bonds) and between layers (one bond). There are two types of dislocations with Burgers vector $\frac{\mathrm{a}}{2}[1 \overline{1} 10]$ : the

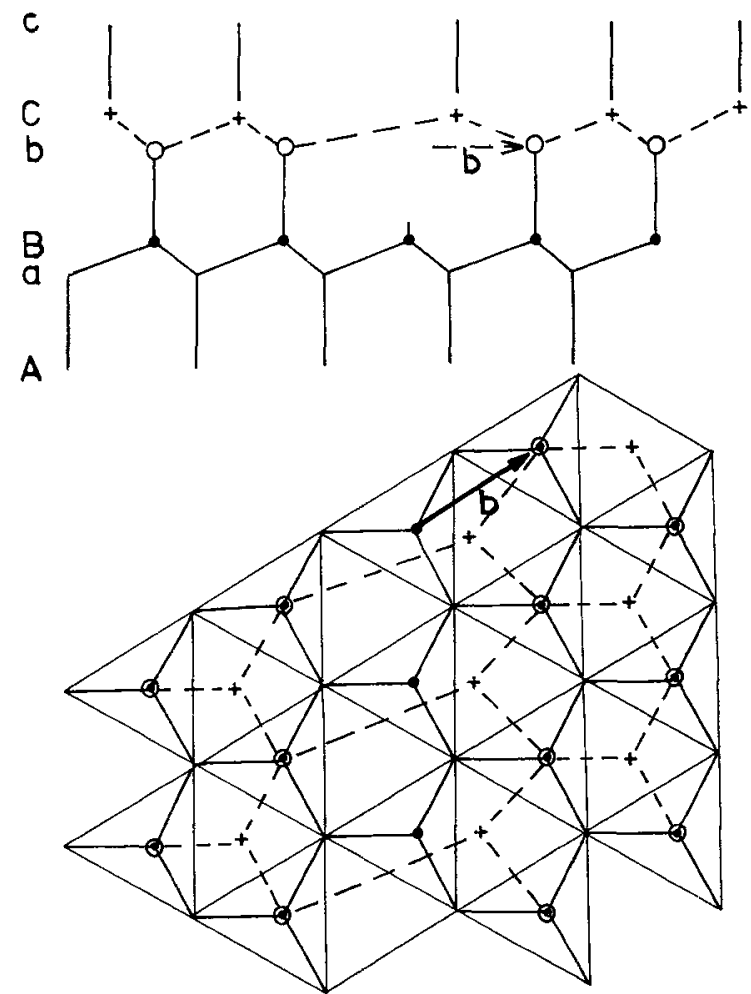

FIG. 1. - A $60^{\circ}$-shuffle set dislocation, projected on the (112) plane $(a)$ and the (111) plane (b).

first displaces two neighbouring layers one relative to the other, whereas the glide plane of the second type separates the two planes of one layer. Hirth and Lothe [2] call the first type shuffle set, the second giide set dislocations for reasons to be discussed in the following. Because of the different number of bonds to 
be cut and regarding the larger distance of the two planes of atoms bordering the glide plane the shuffle set dislocations until recently were thought to be the only agents of plastic deformation.

In the core of any dislocation there must exist a severe disarrangement of the tetrahedral coordination typical for the diamond structure. But dissociating the two sets of dislocations into Shockley partials bordering a stacking fault ribbon brings to light another difference between both. In the case of a dissociating glide set dislocation the breaking and distortion of bonds remains confined to the core of the partials, the stacking fault being compatible with the tetrahedral coordination of atoms. In the case of shuffle set disIocations the stacking fault would be a surface with severely distorted bond angles. Therefore it is agreed upon that shuffle set dislocations cannot split in a narrow sense. However, Hornstra [3] suggested a dissociation of shuffle set dislocations, later on explained by Haasen and Seeger [4] as an association of the shuffle set dislocation with a stacking fault in one of the neighbouring (111) layers which must be bordered by two Shockley partials of opposite Burgers vector. This associate should have a lower strain energy than the shuffle set dislocation alone, because the most strained bonds in the region of dilatation are somewhat released. The number of broken bonds on the other hand increases by that nucleation of a stacking fault as shows figure 2. It may be assumed that the unpaired electrons in the core of the dislocations form new bonding states lowering their energy in a similar way

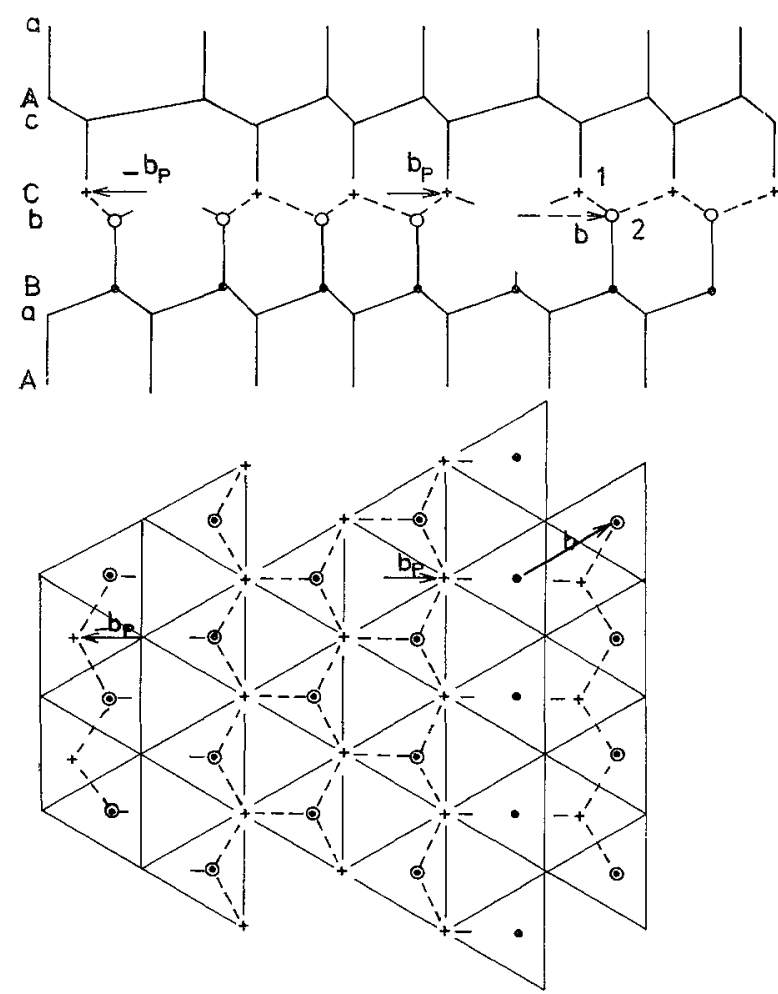

FIG. 2. - Associate of a $60^{\circ}$-shuffle set dislocation (Burgers vector b) with a stacking fault. Projections as in figure 1 . as in the case of irradiation induced point defects [5]. A look at the (111) plane (Fig. 2b) shows that this healing of dangling bonds probably takes place not by simple pair bonding. Therefore the extraneous bonds commonly drawn between the dangling bond atoms in the layers $\mathrm{b}$ and $\mathrm{C}$ are omitted in figure $2 a$. A proof of stability of the associate has to take into account the energies of strain (bent and stretched $\mathrm{sp}^{3}$-hybrid bonds), of the stacking fault and of the totally changed electron states.

The dislocation type under discussion was named shuffle set because the atom numbered 1 in figure $2 a$ moves not by $(-\bar{b})$, as does atom 2 , but by - $\left(\bar{b}-\bar{b}_{p}\right)$, when the dislocation is displaced one lattice distance to the right. This is interpreted by Hirth and Lothe as a diffusive motion of atoms in the dislocation core (shuffling). But in effect the atom 1 is displaced by a vector of the type $\frac{a}{6}<112>$ which seems not to rise special difficulties.

The dissociation of a glide set dislocation is shown in figure 3 for the $60^{\circ}$ dislocation schematically without
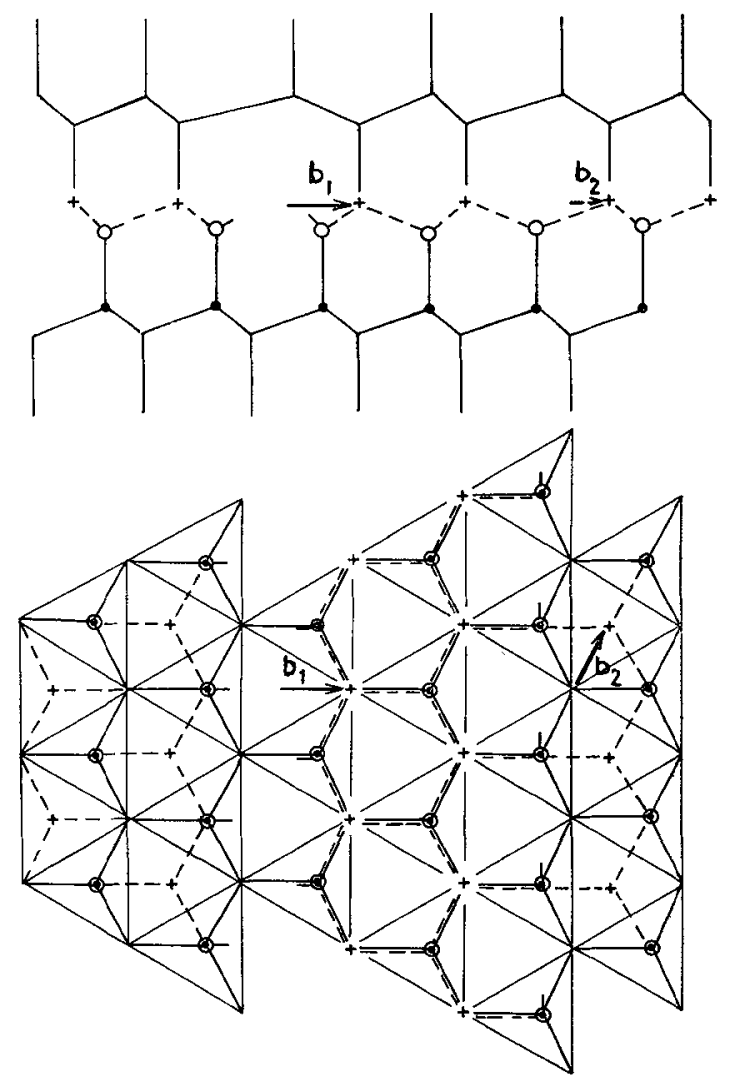

FIG. 3. - A dissociated $60^{\circ}$-glide set dislocation. Projections as in figure 1.

relaxation by bond bending. The arrangement of electrons which don't fit any more into $\mathrm{sp}^{3}$-bonds (dangling bonds) is changed by the splitting, not so their number. Drawing in the same manner the dissociation of dislocations of different character one is led to generalize 
this statement. The only exception to the rule is the screw dislocation : undissociated it may exist without dangling bonds [3]. (This assumption as a matter of fact depends on the degree to which the $\mathrm{sp}^{3}$-bonds can be distorted without losing their character.) Dissociation into two Shockley partials introduces dangling bonds of various types. One may think about a coexistence of shuffle set and glide set dislocations, respectively of shuffle set and (split) glide set segments on the same dislocation. The transition between two segments of different type is made by a jog one atom high. These single jogs accept and emit single vacancies and interstitials respectively whereas each set of dislocations by oneself has double jogs on account of the two sublattices.

Summarizing the discussion of models of the dislocation core it must be admitted that neither the positions of atoms nor the electron states replacing the $\mathrm{sp}^{3}$-states of the diamond structure are known with some accuracy.

3. Experimental methods. - Both problems mentioned in the last sentence are closely interrelated and may be investigated experimentally by spectroscopical methods. Whereas the influence of the dislocations on the electrical and electro-optical properties [6] of the crystal reflects the contribution both of the dislocation core and of its strain field, the paramagnetic electron spin resonance (EPR) should be determined chiefly by the dislocation core. EPR spectroscopy of plastically deformed silicon crystals reveals a rather complicated spectrum [7] which depends strongly on temperature between $6 \mathrm{~K}$ and $300 \mathrm{~K}$. The analysis of the spectrum is impeded by the absence of hyperfine structure. So the spatial distribution of the unpaired electrons causing the EPR cannot yet be deduced. Nevertheless recently several interesting results were obtained [8]. A zero field splitting with the Burgers vector of the primary glide system as its main axis substantiates the existence of groups of at least two electrons with coupled spins in the core of (some ?) dislocations. Furtheron one observes several lines which from the type of their $g$-tensor may be attributed to various orientations of a dangling bond or of a parallel pair bond. Whereas these centers below $70 \mathrm{~K}$ mark $\langle 213\rangle$ directions, lines with the four $\langle 111\rangle$ as dangling bond directions emerge above that temperature. From that one must conclude that the electron states introduced by the dislocations change with temperature or at least that the occupation of different existing states depends on temperature. Further analysis and more refined experimental techniques presumably will help to get a microscopical model of the dislocation core.

Leaving out for the moment the exact knowledge of the core structure the proof that the dislocations are split in silicon and germanium was furnished by means of the weak beam electron microscopy $[9,10]$. All dislocations in silicon deformed at $850^{\circ} \mathrm{C}$ and $1200^{\circ} \mathrm{C}$ were found dissociated. From the separation of the two partials Ray and Cockayne [9] determined a stacking fault energy of $\gamma=(51 \mp 5) \mathrm{erg} / \mathrm{cm}^{2}$. The evaluation of extended nodes resulted in the same energy with a larger uncertainty : $(50 \pm 15) \mathrm{erg} / \mathrm{cm}^{2}$. In the case of germanium the observations are more complicated: after plastic deformation at $520^{\circ} \mathrm{C}$ most of the dislocations were found to be extended, but «most of the dissociated dislocations contained segments that were either constricted or the partial dislocations of which could not be resolved $[10]\left({ }^{1}\right) »$. First orientating weak beam micrographs taken by Wessel in our group show the same characteristics in silicon deformed at $800^{\circ} \mathrm{C}$ (Fig. 4). The density of constricted segments seems to be the larger the higher the deformation
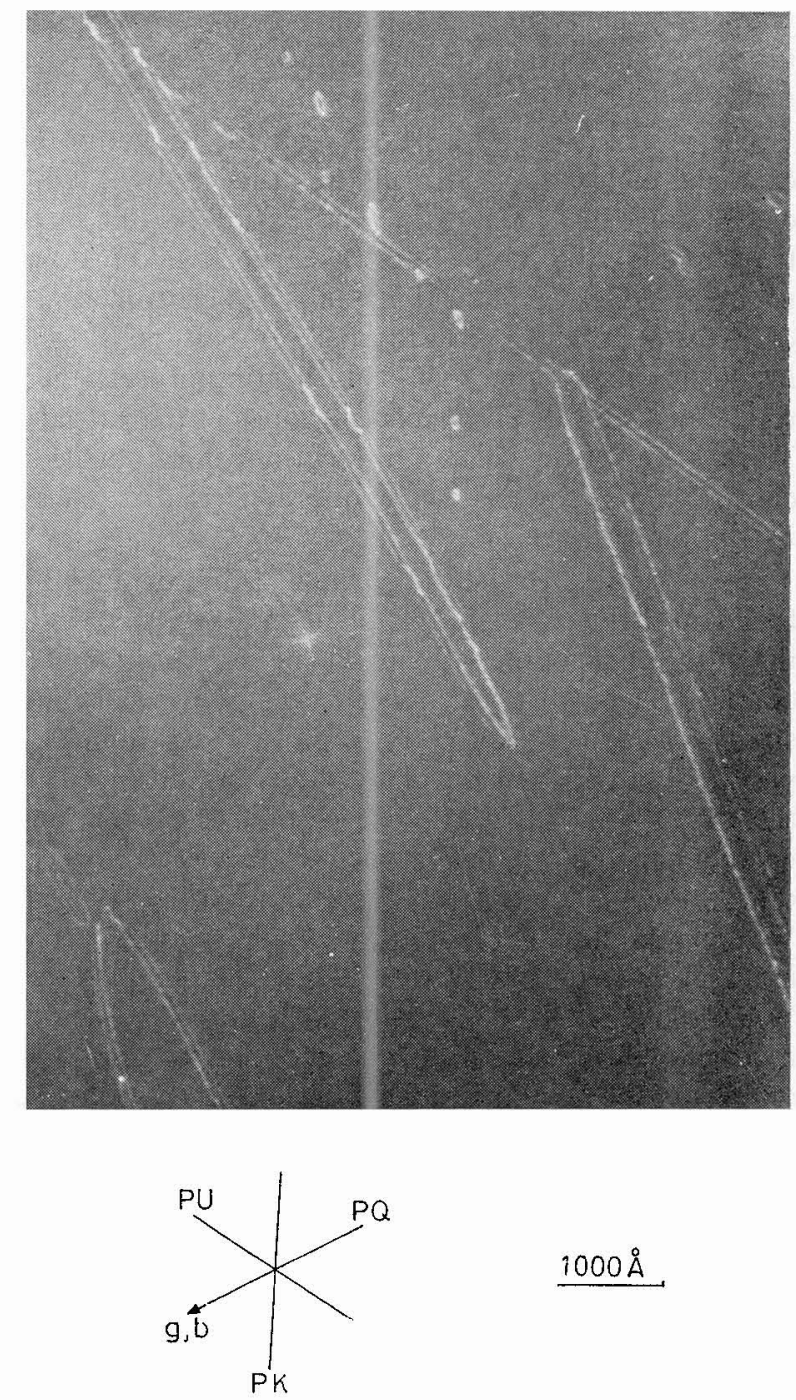

FIG. 4. - Silicon. Dissociated dislocations in the primary glide plane after deformation at $800^{\circ} \mathrm{C}$, cooled under load (1 kp/mm²). (Weak beam micrograph, K. Wessel.)

(1) A. Gomez in Oxford found (isolated) exact screw dislocations in germanium which were dissociated. Two different distances between the two partials were measured (30 and 60-70 \&) (R. Wagner, priv. communic.). Compare the paper of D. J. H. Cockayne, this issue, p. 141. 
temperature was. It is not yet clear if Wessel's constricted segments are identical with an observation made by Ray and Cockayne [9] after annealing silicon at a rather high temperature (10 hours at $1350{ }^{\circ} \mathrm{C}=0.96 T_{\mathrm{m}}$ ). The authors show by a complete analysis of contrast experiments that long segments of mixed dislocations turned into the exact edge orientation and left the glide plane resulting in a garland-like appearance of the dislocation. The segments left in the glide plane remained extended. The authors suggest climb of pure edge segments as an explanation of their findings. Surveying the information drawn from the weak beam electron microscopy so far we may conclude that most of the dislocations in germanium and silicon are dissociated after a deformation at usual temperatures. Most of these dislocations, however, contain segments which are less extended or even perfect. It needs further work to clarify if these constricted segments belong to the shuffle set.

The next question arises about the mobility of extended dislocations. It could be answered by taking cinematographic films of moving partials in the electron microscope [11]. Such experiments are done using the stacks of stacking faults which sometimes originate during localized heating of (100)-foils inside the microscope. A second heating process then results in a slow displacement of groups of the partials. The motion of dissociated dislocations does not need constriction. That answers a question risen formerly in the literature [1].

The process of formation of these groups of stacking faults on many parallel (111) planes in itself is interesting in the connection with our theme. Unfortunately it could never be observed directly because it needs high stresses and runs off very rapidly. The Shockley partials bounding the stacking faults are arranged in the same pattern as the series of perfect dislocations emanated from a single armed Frank-Read source, often observed during such heating experiments [12]. We suppose therefore that in some cases a single partial is separated from its partner by the thermal stresses. When the second partial is fixed, the stress needed is moderate $\left(30 \mathrm{kp} / \mathrm{mm}^{2}\right.$ in the case of germanium). The mobile partial turning around a pole dislocation should form the observed regular stack of stacking faults, the critical step being the passage of the two partials at the end of the first turn. Here one has to assume a stress concentration in the order of magnitude of $100 \mathrm{kp} / \mathrm{mm}^{2}$, not impossible in such experiments.

Putting intrinsic stacking faults one above the other on neighbouring (111) planes results in a twin layer. Indeed deformation twins in germanium were found under special conditions: By undirectional solidification of an alloy of silver and germanium in a strong temperature gradient one may form some kind of a fiber reinforced metal [13]. In the matrix consisting of a solid solution of about 3 at $\% \mathrm{Ge}$ in Ag plates of germanium are embedded all with a [100] axis parallel to the freezing direction $z$. After plastic deformation of those composites at a temperature $T_{\mathrm{d}}$ by tension or compression parallel to the $z$ axis one finds even at $T_{\mathrm{d}}=300^{\circ} \mathrm{C}$ a noticeable multiplication of dislocations in the germanium plates. Full plasticity develops above $T_{\mathrm{d}} \approx 400^{\circ} \mathrm{C}$. In the temperature range $300^{\circ} \mathrm{C} \leqslant T_{\mathrm{d}} \leqslant 400^{\circ} \mathrm{C}$ numerous deformation twins spring up (J. Albrecht, unpubl. results). Figure 5

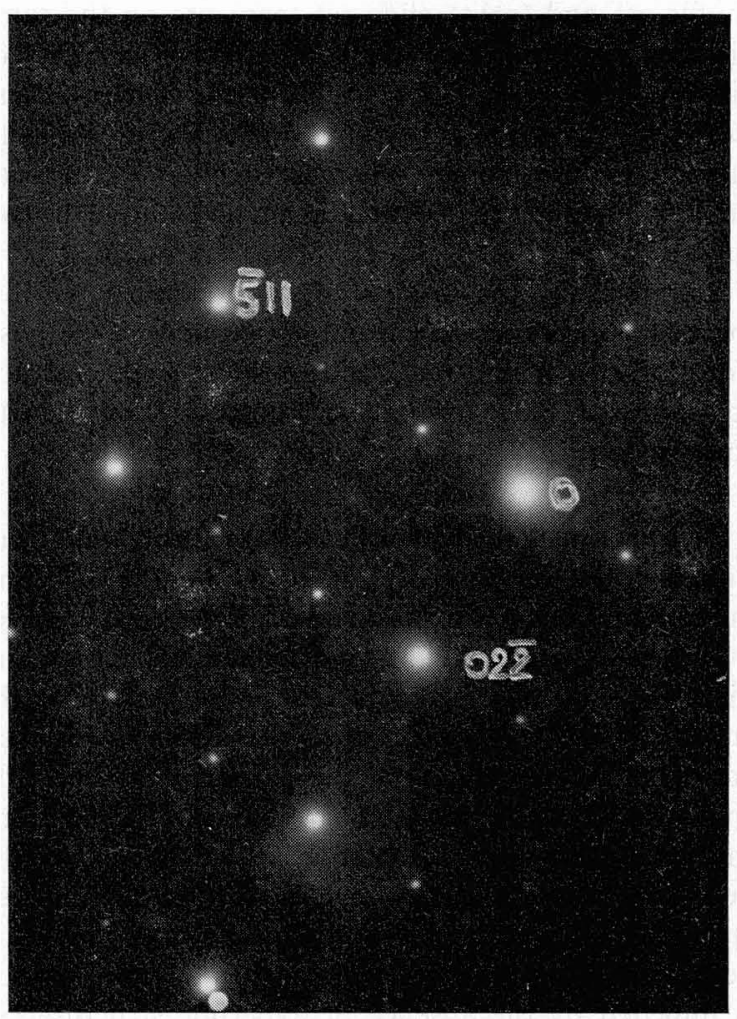

FIG. 5. - Germanium out of a deformed Ag-Ge eutectic composite. Electron diffraction pattern with twin reflexes. (J. Albrecht.)

shows a selected area diffraction pattern which exhibits the extra reflexes of some parallel twins (twin plane $\{111\}$ ). These twins are found preferentially in such regions of the germanium plates where on account of inhomogenities of the distribution of grown-in dislocations no dislocation multiplication took place. That means in regions of high local stress the twin mechanism offers a mode of plastic deformation alternative to the normal dislocation mode. Besides the twins, sheafs of stacking faults were observed like that described in the preceding paragraph. This suggests to interprete the twins as grown out of a dense sheaf of stacking faults. From the macroscopical stress, using the rule of mixture, one may calculate the resolved shear stress reached in the glide systems of the germanium fibers. The resulting stress $\left(\tau=36 \mathrm{kp} / \mathrm{mm}^{2}\right.$ at $300^{\circ} \mathrm{C}$ ) is high enough to separate two partials but one must assume pronounced stress concentrations to enable the partials to pass on neighbouring glide planes. Probably this points more to a ratched-pole 
mechanism than to a pure pole mechanism [2]. The thickness reached by the twins appears to be restricted to about 400 A . Like in fcc metals deformation twins are only found at a relatively low deformation temperature. In the literature [2] in this connection was suggested a stronger temperature dependence of the Peierls stress for perfect dislocations than for partial dislocation. This hypothesis seems to be more qualified for diamond like crystals than for densily packed metals.

4. Plastic deformation. - Now we consider the conclusions to be drawn from the plastic deformation of macroscopic single crystals. The most prominent of the plastic properties of diamond like crystals is the exponential temperature dependence of the dislocation velocity [14]. This results in a restriction of ductility for times commonly used in experiments to the range $T_{\mathrm{d}} \geqslant 0.55 T_{\mathrm{m}}\left(T_{\mathrm{m}}\right.$ absolute melting temperature $)$. The stress may be increased for compensation, but to a limited degree because of the onset of brittle fracture, the critical stress of which decreases with falling temperature [15]. An indirect consequence of the immobility of dislocations below a rather high temperature is the low density of dislocations in asgrown crystals $\left(N_{0} \approx 10^{2}-10^{3} \mathrm{~cm}^{-2}\right.$ without special precautions). The stress strain curve under dynamical conditions $(\dot{\varepsilon}=$ const.) of an asgrown crystal exhibits at the very beginning a pronounced yield point phenomenon of the type first discovered by Johnston and Gilman [16] in LiF. Between upper and lower yield stress the dislocation density $N$ raises to values common in metals $\left(\approx 10^{8} \mathrm{~cm}^{-2}\right)$. Otherwise the stress strain curve looks much the same as in fcc metals possessing three stages the length of which depends on the deformation conditions in the same way as in copper. The stage III of dynamical recovery will be handled with later.

Recently we investigated the origin of glide dislocations in germanium near the upper yield point [12]. As expected from the definite relationship between $N_{0}$ and the upper yield stress most of the dislocations are produced by sources which are connected with grown-in dislocations. The crystal surface does not play a prominent role. On Lang topographs (Fig. 6) the appearance of the dislocation spirals is exactly the same on a larger scale as was seen in thin foils heated in the electron microscope. So we are justified in supposing that the prevailing multiplication process at the beginning of the deformation is the single armed Frank-Read mechanism starting at segments of grown-in dislocations laying in one of the glide planes. (In spite of the orientation for single glide the dislocation activity on the primary glide plane exceeds that on the other glide planes not before a later stage.) On figure 6 one may detect the process by which the spreading of dislocations out of the few glide planes with dislocation sources takes place : after piling up several turns of the dislocation spiral one or more arms

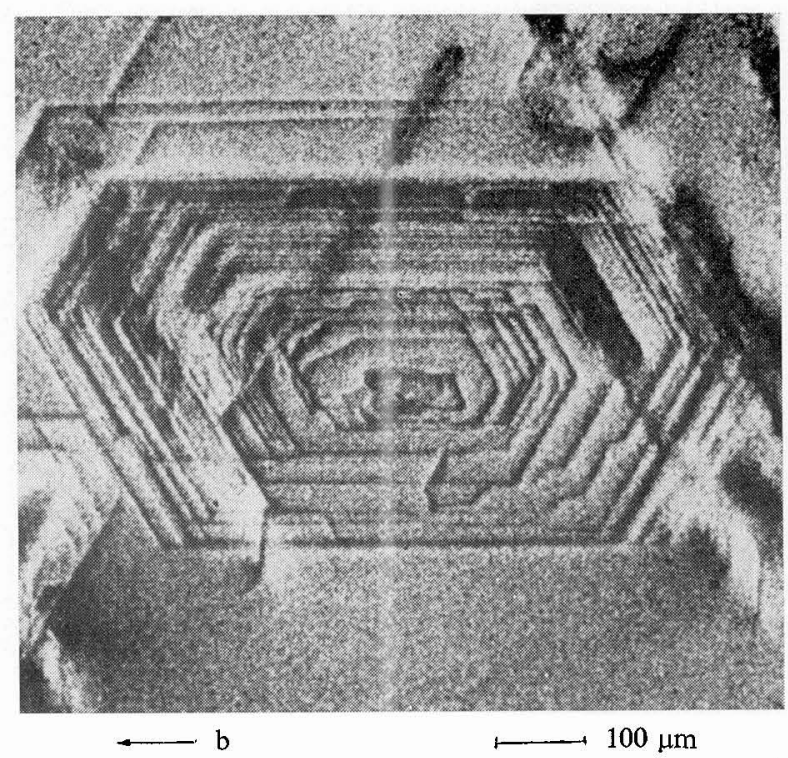

Fig. 6. - Germanium, deformed at $520^{\circ} \mathrm{C}, \varepsilon=4 \times 10^{-3}$, cooled under load $\tau=4 \mathrm{kp} / \mathrm{mm}^{2}$. Dislocation source with cross gliding screw segments. (Lang topograph, R. Meingast.)

cross glide to another parallel glide plane. As the orientation of the crystal is such that the cross glide plane gets no shear stress from the applied stress internal stresses must be responsible for the cross gliding as proposed by the theory of Mendelson [17]. Meingast [12] succeeded in preparing such cross glide events for the electron microscope by a special multistage technique. The micrograph shown in figure 7 is taken from a thin foil parallel to the cross glide plane $\mathrm{Q}\left({ }^{2}\right)$. In the region between two packets of active primary glide planes there are dislocations which spread in the cross glide plane. Replicas of the crystal surface too show activity on $Q$ between glide lines parallel to the primary glide plane $P$. Besides answering the question of dissemination of dislocations discussed for a long time, in our context this means cross gliding screw dislocations from the very beginning of plastic deformation. This is in agreement with findings of Schaumburg [18]. It also is an example for the conformity of the processes determining the plastic properties of germanium and e. g. copper where Eßmann [19] and Basinski and Basinski [20] found the same, the last named without to apply stress in $\mathrm{Q}$. That cross glide is a frequent event during stage $I$ of the stress strain curve had been concluded in an earlier work [21] from the absence of screw dislocations and from the so-called $Q$-traces. These are lines parallel to the Burgers vector in the primary glide plane, $30-100 \mu \mathrm{m}$ long, along which are arranged many ends of long edge dipoles, small loops and steep inclined dislocations (super-jogs). Alexander explained this characteristic phenomenon,

(2) In the figures 4, 6 and 7 one recognizes that on account of the strong Peierls potential the $\langle 110\rangle$ directions are strongly prefered by the dislocations. It is our impression that this preference ends with the onset of crossglide. So one finds sometimes perfect $\langle 110\rangle$ dislocations intermixed with strongly bent ones. 

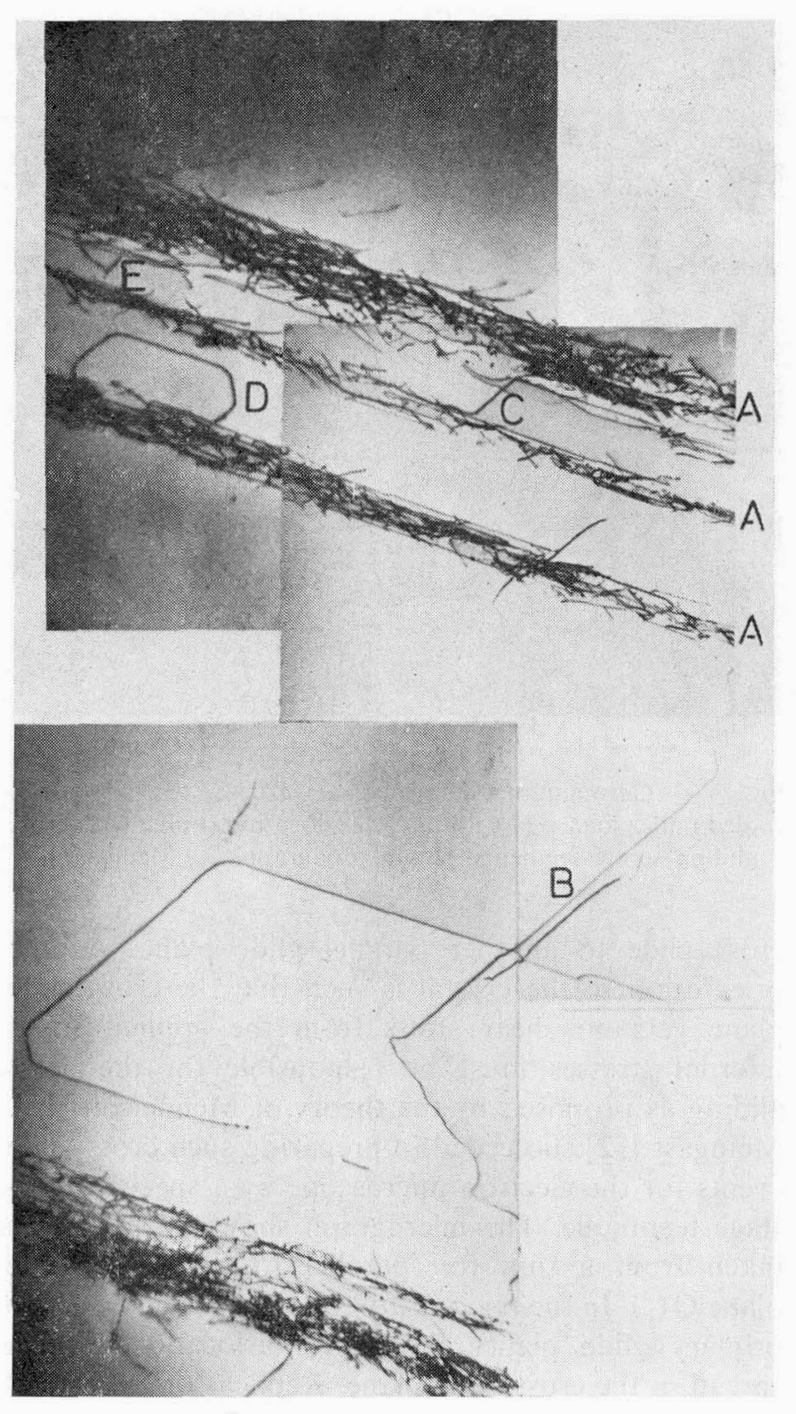

$\longmapsto 1 \mu \mathrm{m}$

FIG. 7. - Germanium, deformed at $520^{\circ} \mathrm{C}, \varepsilon=2 \times 10^{-3}$ cooled under load $\tau=3.4 \mathrm{kp} / \mathrm{mm}^{2}$. Electron micrograph of the cross glide plane. (R. Meingast.)

which is seen in silicon too, as traces of moving edge segments on $\mathrm{Q}$ formed by cross gliding screw dislocations. Some of these edge segments are preserved in the $Q$-traces in form of the super-jogs.

Unfortunately in all experiments described so far only internal stresses, quantitatively unknown, were operating on the cross glide plane. For that reason it is impossible at present to examine the importance of stress assisted constriction for cross gliding.

In the case of fcc metals the temperature dependence of the stress $\tau_{\mathrm{II}}$ characteristic for the beginning of dynamical recovery may be explained by the theory of thermally activated cross glide of screws. Testing $\tau_{\mathrm{III}}(T, \dot{\varepsilon})$ of germanium single crystals Alexander and Haasen [22] found a different relationship which they attributed to climb of edge dislocations following a theory of Weertman [23]. Later on Weiß [24] conducted an extensive investigation of the fanning of glide bands [22]. He confirmed that fanning of many glide bands formed by nearly edge dislocations of the primary glide system is the feature characteristic for crystals deformed in stage III of the stress strain curve (Fig. 8). But the fanning events turned out to be

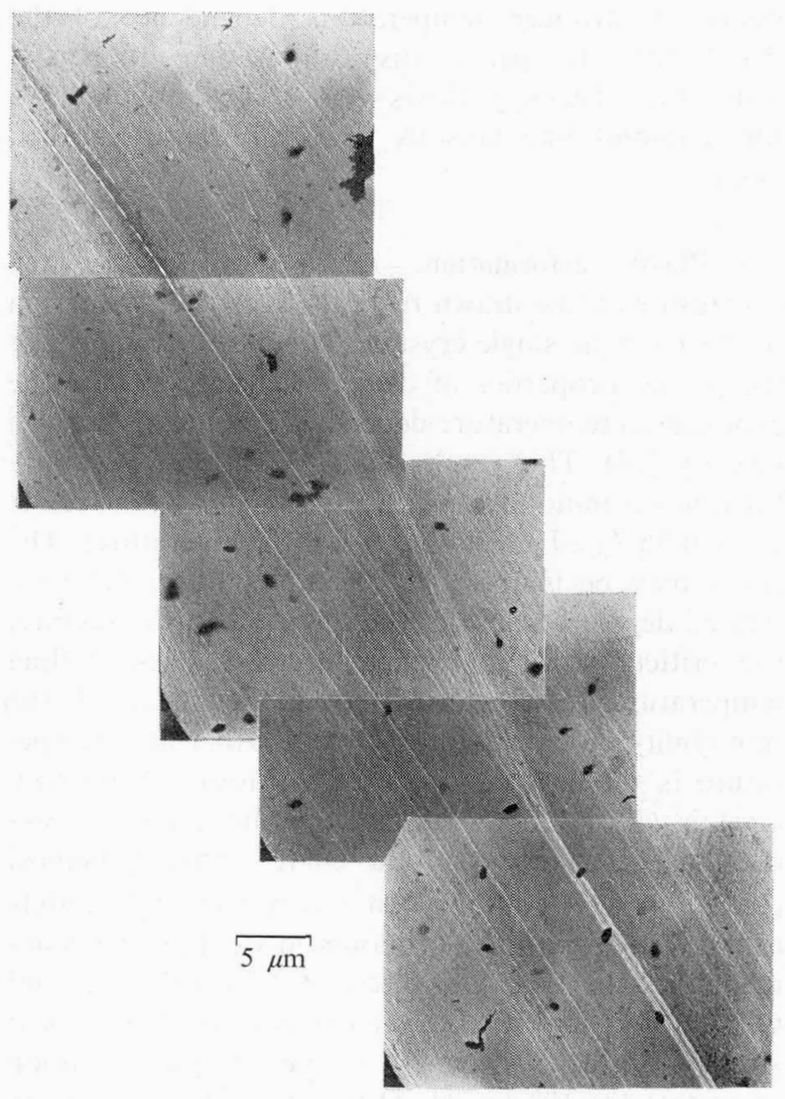

Fig. 8. - Germanium, deformed at $520^{\circ} \mathrm{C}$ into stage III of the stress strain curve $(\varepsilon=0.68)$. Fanning glide bands at the side face of the crystals. (Shadowed replica, L. Weiss.)

confined to the same end of all fanning glide bands on the whole side-face of the crystal. When one calls this end looking at the (1) $\overline{4} 2)$ face the right end then on the $(14 \overline{2})$ face the glide bands fan at their right ends too. A second unsymmetry concerns the direction of the deviation of the glide bands : all fanning events were of the vacancy absorption type (removal of the extra half plane). At the same time Strunk and Eßman [25] obtained rather similar results investigating copper single crystals deformed at $200^{\circ} \mathrm{C}$. As their crystals had a circular cross section in contrast to Weiß's saw-cut crystals they were able to show that the fanning was concentrated in two opposite quadrants of the circumference. Strunk and Eßmann identified these quadrants to be those regions where absorption of vacancies shifts an edge dislocation in the same direction out of its glide plane as a cross gliding screw dislocation is moved by the applied stress component in the cross glide system. From that they concluded that the fanning of glide bands of copper at $200^{\circ} \mathrm{C}$ is determined by the combined cross glide-climb motion 
of mixed dislocations. The acceptance of this interpretation seems attractive in view of the similarity of the experimental findings. But there is an important difference between both cases : the compression axis of the crystals used by Weiß was parallel to the cross glide plane so that no stress component $\tau_{0}$ existed during the deformation. So the uniformity of the cross glide-climb direction remains unexplained. An estimate of the number of vacancies needed for the observed nonconservative motion of dislocations resulted in values $\left(c_{\mathrm{v}} \approx 2 \times 10^{-5}\right)$ which may be reached in stage III of the stress strain curve. Certainly the vacancies present in thermal equilibrium are of no importance as their density is very low in germanium [26] (at $600^{\circ} \mathrm{C}$ $c_{\mathrm{v}} \approx 10^{-10}-10^{-12}$ ).

The measurement of the latent hardening of secondary slip systems is a further deformation experiment from which possibly some information about dissociation may be drawn. Those experiments were carried out by John L. Crawford in Köln (unpubl. results). From a crystal deformed by compression just beyond the lower yield point he cuts secondary specimens which were oriented for slip on another (secondary) glide system. The reliability of the results was proved by secondary specimens prepared in the same manner but without changing the orientation. In this way it was shown that cooling from the deformation temperature $\left(581^{\circ} \mathrm{C}\right)$, preparing the secondary specimen, and heating for the second deformation did not change the flow stress. The results are shown in table I. The secondary glide systems are characterized in the usual manner (first letter : glide plane ; second letter : cross glide plane). $\mathrm{P}$ represents the primary, $\mathrm{U}$ the critical, $\mathrm{K}$ the conjugate and $\mathrm{Q}$ the cross glide plane. $L$ is the ratio of the flow stresses at the end of the first and that at the beginning of the second deformation: $L=\tau_{1} / \tau_{2}$. In some cases the second deformation started with a small yield point. Then for $\tau_{2}$ the lower yield stress was taken. This is because at this special stress the optimal dislocation density in the operating glide system is reached. Here we know the portions of the stress contributed by the lattice friction and by the internal back stress [1]. For the lower yield stress applies :

$$
\tau_{1 \mathrm{y}}=\left(\frac{m}{2}+1\right) A \sqrt{N}
$$

where

$$
m=\frac{\partial \ln v}{\partial \ln \tau_{\text {eff }}} \text { and } \tau_{\text {eff }}=\tau-A \sqrt{N}
$$

$\left(v\left(\tau_{\text {eff }}, T\right)\right.$ is the velocity, $N$ the density of the mobile dislocations). The first term $(\mathrm{m} / 2)$ of the sum (1) stems from the lattice friction, the second represents the hardening by elastic interaction of the dislocations of the active slip system. At the lower yield point both contributions turn out to be proportional to $\sqrt{N}$. The stress $\tau_{1}$ practically equals the lower yield stress of the primary glide system :

$$
\tau_{1}=\left(\frac{m}{2}+1\right) A \sqrt{N_{1}} .
$$

The (lower) yield point of the second deformation is reached when

$$
\tau_{2}=\left(\frac{m}{2}+1\right) A \sqrt{N_{2}}+C \sqrt{N_{1}} .
$$

The term $C \sqrt{N_{1}}$ takes into account the flow stress contributed by the interaction with the dislocations of the primary system $\mathrm{PQ}$, now forming a forest. Only $C$ depends on the special mechanism of dislocationforest interaction. The optimal dislocation density $\mathrm{N}_{2}$ equals that of the primary system $N_{1}$ because $N_{\text {ly }}$ is unequivocally determined by $T$ and $\dot{\varepsilon}[1]$. It follows :

$$
\frac{\tau_{2}}{\tau_{1}} \equiv L=1+\frac{2}{m+2} \frac{C}{A} .
$$

The latent hardening ratio turns out to be independent of stress and (through $m$ ) weakly to change with temperature. This was verified by an experiment at $520^{\circ} \mathrm{C}$.

TABLE I

Latent hardening of secondary glide systems in germanium

Products of cutting and

Sec. system reaction

$\begin{array}{ll}\overline{\text { KQ }} & \mathrm{JJ}(\overline{\mathrm{LC}}) \\ \mathrm{UK} & \mathrm{JJ}(\text { Hirth}) \\ \text { QK } & \text { JK } \\ \text { UP } & \text { KJ } \\ \text { QP } & \text { KK }\end{array}$

$$
\text { Latent hard. ratio } \mathrm{L} \quad \mathrm{Cu}, 20^{\circ} \mathrm{C} \text {, stage I }
$$
$\mathrm{Ge}, 581^{\circ} \mathrm{C}\left({ }^{1}\right) \quad$ (from ref. [29])
$1.69 \pm 0.01$
$1.44 \pm 0.01$
$1.58 \pm 0.03$
$1.68 \pm 0.03$
$2.18 \pm 0.05$

$\mathrm{Ge}: C / \mathrm{Gb}$
--
0.28
0.19
0.26
0.28
0.5

$\mathrm{d} \tau / \mathrm{d} \varepsilon$

$\mathrm{s} \leqslant$ prim

$\mathrm{s}>$ prim

$\mathrm{s}<$ prim

$\mathrm{s}<$ prim

$\mathrm{s} \gg$ prim

(1) J. L. Crawford, unpubl. results. 
Since $[1] A(\mathrm{Ge}) \approx 0.25 \mathrm{~Gb}$ and $[18] \bar{m}\left(581^{\circ} \mathrm{C}\right)=1.4$ we may calculate from $L$ the value $\frac{C}{\mathrm{~Gb}}$ for the investigated secondary systems (table I).

The secondary systems are different as well in their ability to form dislocation junctions as in the extra segments (jogs or kinks) which are introduced into the dislocations forced to cut [27-28]. The ,symbol JK means : By cutting one another the primary dislocations receive jogs, the secondary kinks. The system belonging to the class JJ must be divided into two groups : one may form Lomer-Cottrell barriers, the other with orthogonal Burgers vectors could form Hirth locks. In contrast to the prediction made by Hirth [27] the system UK out of this group exhibits the lowest $C$ value of all systems investigated. The same found Jackson and Basinski [29] in copper. Also the systems favouring the formation of Lomer-Cottrell barriers by no means have a larger latent hardening ratio than others - again in agreement with [29]. Quite a different result from Jackson and Basinski we get looking at the cross glide system QP. This is the only secondary system which may use some of the primary dislocations. In spite of this fact and of the absence of jogs the latent hardening ratio is the largest one observed. The dislocations of both systems do not form reaction products but as they have the same Burgers vector they partly repel strongly, partly form a three-dimensional network which may explain the extremely strong work hardening during the second deformation.

Schoeck and Frydman [28] calculated the contribution to the flow stress made by junctions between glide and forest dislocations for the case of a completely random forest. Making some further special assumptions they got values for $C / \mathrm{Gb}$ which are well in agreement with our results $(0.30$ for screws and 0.27 for edge dislocations). It would be worth to sum up the contributions of the dislocation reactions occuring between the dislocation forest on the primary glide plane and the particular secondary glide system in our case, instead of averaging over a random forest. Then one could decide if our results mean that the flow stress caused by the forest is dominated by the reactive trees. In any case : Comparing the measurements made on different secondary systems one is able to conclude that the Lomer-Cottrell barriers do not affect the flow stress or the initial work hardening rate in the secondary system more than other barriers or junctions.

5. Conclusions. - We are now sure that dissociated dislocations play a prominent role in germanium and silicon and, as show first experiments, in IIIV-compounds too. A number of peculiarities seen on the weak beam micrographs probably will be clarified in the near future, especially by the use of a wider range of deformation and annealing conditions. The plastic properties of diamond like crystals and fcc metals are rather similar provided one makes his experiments above the brittle ductile transition temperature of the first named substances. This is reflected by a surprisingly far-reaching agreement of the dislocation pattern as revealed by electron microscopy. This may be understood because beyond a certain dislocation density the dislocation interactions and reactions predominate such aspects as the Peierls potential and the character of bonding. The detection of dissociation explains why the dislocation interactions are very similar in both classes of materials and why germanium resembles more to copper than to aluminium.

Acknowledgments. - I am indebted to J. L. Crawford (1972 on leave from the University of Witwatersrand, Johannesburg) and to my coworkers R. Meingast, $\mathrm{L}$. Weiss and $\mathrm{K}$. Wessel for leaving unpublished results. To them, H. Gottschalk and S. Mauri I thank for valuable discussions and help.

\section{References}

[1] Alexander, H. and HaAsen, P., Sol. Stat. Phys. (Acad. Press New York) 22 (1968) 27

[2] HiRTH, J. P. and LOTHE, J., Theory of Dislocations (McGraw Hill, New York) 1968.

[3] Hornstra, J., J. Phys. Chem. Solids 5 (1958) 129.

[4] HaAsen, P. and SeEger, A., Halbleiterprobleme IV (Vieweg Braunschweig) 1958 p. 68

[5] Watkins, G. D. and Corbett, J. W., Phys. Rev. A 138 (1965) 543.

[6] Labusch, R. and Schröter, W., in Dislocation Theory (Ed. F. R. N. Nabarro) in press.

[7] Alexander, H., Labusch, R. and SAnder, W., Solid State Commun. 3 (1965) 357.

[8] Alexander, H., Nordhofen, B. and Weber, E., Proc. 18 Ampere Congr. N 11, Nottingham 1974 in press.

[9] Ray, I. L. F. and Cockayne, D. J. H., Proc. R. Soc. A 325 (1971) 543

[10] Häussermann, F. and Schaumburg, H., Phil. Mag. 27 (1973) 745 .

[11] Meingast, R. and Alexander, H., Phys. Stat. Sol. (a) 17 (1973) 229.

[12] Meingast, R., Thesis Univ. Köln 1974 to be publ.
[13] Krummheuer, W. R. and AleXander, H., Z. Metal. 62 (1971) 129 ; J. Mat. Sci. 9 (1974) 229.

[14] Chaudhuri, A. R., Patel, J. R. and Rubin, L. G., J. Appl. Phys. 33 (1962) 2736.

[15] AleXander, H., Z. Metal. 52 (1961) 344.

[16] Johnston, W. G. and Gilman, J. J., J. Appl. Phys. 30 (1959) 129.

[17] Mendelson, S., J. Appl. Phys. 43 (1972) 2113.

[18] SchaumburG, H., Phil. Mag. 25 (1972) 1429.

[19] Essmann, U., Phys. Stat. Sol. 12 (1965) 707.

[20] Basinski, Z. S. and Basinski, S. J., Phil. Mag. 9 (1964) 51.

[21] AleXander, H., Phys. Stat. Sol. 26 (1968) 725.

[22] Alexander, H. and HaAsen, P., Acta Metall. 9 (1961) 1001

[23] Weertman, J., J. Appl. Phys. 26 (1955) 1213 ; 28 (1957) 362.

[24] Werss, L., Diploma Thesis Univ. Göttingen 1968.

[25] Strunk, H. and Essmann, U., Ż. Metal. 60 (1969) 367.

[26] Seeger, A. and Swanson, M. L., Int. Symp. on Lattice Defects in Semicond., Tokio (1966).

[27] HrR TH, J. P., J. Appl. Phys. 32 (1961) 700.

[28] Schoeck, G. and Frydman, R., Phys. Stat. Sol. (b) 53(1972) 661.

[29] JaCkson, P. J. and BAsinski, Z. S., Can. J. Phys. 45 (1967) 707. 